\title{
Study of the Digestate as an Innovative and Low-Cost Adsorbent for the Removal of Dyes in Wastewater
}

\author{
Sicong Yao ${ }^{1, *} \mathbb{C}$, Massimiliano Fabbricino ${ }^{1}$, Marco Race ${ }^{2}\left(\mathbb{D}\right.$, Alberto Ferraro $^{1}{ }^{1}$, \\ Ludovico Pontoni ${ }^{1}$, Oriella Aimone ${ }^{1}$ and Yao Chen ${ }^{3}$ \\ 1 Department of Civil, Architectural and Environmental Engineering, University of Naples Federico II, \\ Via Claudio 21, 80125 Naples, Italy; fabbrici@unina.it (M.F.); alberto.ferraro3@gmail.com (A.F.); \\ ludovico.pontoni@unina.it (L.P.); o.aimone@gmail.com (O.A.) \\ 2 Department of Civil and Mechanical Engineering, University of Cassino and Southern Lazio, Via di Biasio 43, \\ 03043 Cassino, Italy; Marco.race@unicas.it \\ 3 College of Architecture and Environment, Sichuan University, Chengdu 610065, China; chenyao@scu.edu.cn \\ * Correspondence: sicong.yao@unina.it; Tel.: +39-3894-797-963; Fax: +39-081-7683-481
}

Received: 18 June 2020; Accepted: 13 July 2020; Published: 16 July 2020

check for updates

\begin{abstract}
Digestate, as an urban solid waste, was considered as an innovative adsorbent for colorant polluted wastewater. Batch adsorption experiments were carried out using digestate as an adsorbent material to remove various dyes belonging to different categories. The removal rate and adsorption capacity of dyes were evaluated and the dose of digestate, contact time, and initial dye concentration were studied. The maximum removal rate was approximately $96 \%$ for Methylene Blue. The equilibrium time for the Methylene Blue was $4 \mathrm{~h}$, while for other dyes, a longer contact time was required to reach the equilibrium. The suspicion of colloidal matter release into the solution from solid fraction of the digestate led to the investigation of the consequence of a washing step of the digestate adsorbent upstream the adsorption experiment. Washed and not washed adsorbents were tested and the differences between them in terms of dye removal were compared. Moreover, experimental data were fitted by pseudo-first order, pseudo-second order, and intra-partial diffusion kinetic models as well as Langmuir, Freundlich, and Sips isotherm models. The results from fitted models showed that the adsorption of various dyes onto the digestate was mostly well fitted by the Langmuir isotherm and pseudo-second-order kinetic model.
\end{abstract}

Keywords: digestate; dye; adsorbent; adsorption; kinetic model; isotherm model

\section{Introduction}

The textile industries' wastewater pollution is becoming one of the environmental issues drawing more and more attention owing to the unlimited release of wastewater into the surface water body [1]. With the expansion of synthetic dyes' production scale, the dye industry has been in fierce competition of manufacturing technology in recent years owing to its advantages in high washability and isolation resistance [2]. Because the raw materials, intermediates, and products from the dye industry are almost aromatic nitro and amino compounds and their derivatives, these products carry huge toxicity and carcinogenic risk during the production process [3]. The solubility of synthetic dyes in aqueous solution is relatively high and reactive groups in dyes can form covalent bonds with fibre.

Although the discharge of dyes into water only represented a small portion of the overall pollutants release if compared with other more hazardous wastewaters, the control of textile wastewater was considered as one of the most important environmental issues during recent decades, especially owing to the high visibility of dyes even discharged at very low concentrations [4]. Dyes in wastewater can absorb light, reduce the transparency of water bodies, consume a large amount of oxygen in water, 
cause hypoxia in water bodies, affect the growth of aquatic organisms and microorganisms, damage the self-purification of water bodies, and easily cause visual pollution. The heavy metals in dye wastewater, such as chromium, lead, mercury, arsenic, zinc, and other heavy metal salts, cannot be biodegraded. They can exist for a long time in the natural environment and continue to pass through the food chain and accumulate in the human body. If dye wastewater was discharged directly without treatment, it would cause great threats to the stability and cleanness of human drinking water source [5].

Direct Yellow 27 (DY27) and Acid Red 66 (AR66) generally belong to azo dye categories and are applied widely in different processes such as silk, wool, leather, jute, cotton dyeing, biological staining, dermatology, veterinary medicine, green ink manufacture, textile dyeing, and paper printing [6]. As azo dyes have functional groups that react with a wide variety of other materials through the establishment of covalent bonds, some harmful side effects of utilizing azo dyes were reported [7].

Reactive azo dyes such as Reactive Black 5 dye (RB5) and Reactive Violet 5 (RV5) are commonly seen not only in textile industry, but also dyeing for paper printing, leather, and food. The azo group in azo dyes is often connected with one or more aromatic ring systems to form a conjugated system as a chromophore of the dye. Under certain conditions, azo dyes can be decomposed and reduced to more than 20 aromatic amines that are carcinogenic. These dyes could change the DNA structure of the human body during long-term contact, thereby causing disease and inducing malignant tumors [8].

Methylene Blue (MB) belongs to the category of basic dyes, known as difficult to handle and highly soluble. MB is a widely used dye in industry, and it has one of the highest degrees of danger, as it presents corrosive and irritant characteristics. Some animal experiments have shown that MB may be carcinogenic in nature [9].

Various treatment technologies have been considered for dye removal from wastewater, including chemical precipitation [10], biological treatment [11], and adsorption [12]. Owing to the complex components of dye wastewater, high chemical oxygen demand (COD) and biochemical oxygen demand (BOD) concentration, suspended solids, and many refractory substances, dye wastewater treatment technology has received the full attention from water treatment researchers worldwide.

Njoku et al. [13] used rambutan (Nephelium lappaceum) peel as raw material for activated carbon preparation. The adsorbents were prepared by the $\mathrm{KOH}$ activation method to remove acid yellow 17 (AY 17) with different initial dye concentrations (from 50 to $400 \mathrm{mg} / \mathrm{L}$ ). The maximum adsorption capacity by rambutan peel activated carbon and the equilibrium adsorption time of AY 17 removal were obtained.

Garg et al. [14] investigated an adsorptive removal method using a synthesized zeolite with fly ash as raw material for Amido black 10B; the maximum removal rate was $75.3 \%$ at the optimum dosage of zeolite, and the equilibrium time and the stirrer speed of the experiment were evaluated in this study.

On the contrary, Qiu et al. [15] only observed an Amido black removal efficiency of $16.3 \%$ by using natural zeolite. Qiu's study did not demonstrate an efficient colorant removal rate, and the dosage of Garg's results seemed to be relatively high and required a higher stirring speed, which might cause higher economical consumption and low efficiency. The current treatment situations for dye wastewater urgently need an efficient and economical adsorbent.

Adsorption has become a promising method in the field of wastewater treatment based on its ability to selectively gather certain compounds. The adsorption process is capable of removing suspended, dissolved, and colloidal pollutants, which are still present in the effluent downstream of secondary treatments [16]. The active sites usually exist on the surface, but also inside the adsorbent material structure that hosts the particles contained in the water until the equilibrium condition [17].

Hence, adsorption has great potential as a solution for dye removal from wastewater thanks to its technical feasibility, flexibility, and operation simplicity [18]. Numerous new adsorbents were produced and studied from different bioresources for dye removal. These bio-adsorbents have been considered promising with the large availability and low cost of their raw materials [19,20].

The increasing rate of urbanization has resulted in the massive production of organic solid wastes. The improper management of organic waste such as digestate encroaches on a large amount of farmland 
and causes pollution to the soil, especially when various substances leach into the soil with rainwater, which could cause soil contamination by harmful toxic chemicals, pathogens, and radioactive materials. Moreover, this pollution could spread with the flowing water and underground water, and thus lead to the expanded soil polluted area. Furthermore, the improper stack of digestate waste pollutes the atmosphere by emitting a foul odor, poisonous gas, particulate diffusion, spontaneous combustion, and incineration.

Therefore, when treating waste materials such as digestate as they are presented in large quantities, economic and environmental compatibility should be considered under this urgent circumstance [21]. In fact, waste materials represent a very high expenditure to be made, as they should be disposed of appropriately. Reuse of these materials would be an enormous advantage if a considerable method was implemented. In addition, producing adsorbing materials at very low or even zero costs using raw digestate material is economical. It is clear that investing research into these materials with regard to wastewater treatment is an attractive perspective [22].

Hence, digestate is valuable as a potential excellent organic adsorbent [23]. The preparation of digestate adsorbents has superiority in industrial solid waste reduction and highly-effective adsorbents production with low cost [24]. However, barely any research focused on digestate adsorption properties for dyes' removal, while literature studies mainly reported experimental activities on the development of bioreactor and the application of digestate as a nitrogen and phosphate source for farmland fertilization [25,26].

Recent investigations [27] have shown that dissolved organic matter (DOM) may have a fundamental effect on the pollutants present in aqueous solutions. Dissolved organic matter may hence interfere with adsorption equilibria [28]. For this reason, washing treatment of digestate was proposed as a process for partial elimination of DOM released by the digestate itself.

In this study, batch adsorption experiments were carried out by the use of digestate as an adsorbent material to remove textile dyes from simulated wastewater. The experiments were carried out in laboratory from Department of Civil, Architectural, and Environmental Engineering at University of Naples Federico II, Naples, Italy, from May till October 2019. The removal rate and adsorption capacity of dye contaminants were evaluated and the optimal dose of digestate, contact time, and initial dye concentration were studied in order to evaluate the effect of each single experimental factor during the adsorption process. The results on the optimized dosage of digestate, the equilibrium reaction time, and initial dye concentration were also used for further mathematical model fitting. Model fitting was carried out through pseudo-first order, pseudo-second order, and intra-particle diffusion models in order to identify the best kinetic fitting model to describe the entire adsorption interactions between digestate and dye wastewater. Further model studies were also carried out using Langmuir, Freundlich, and Sips isotherm models in order to better clarify the adsorption phenomena of dyes onto the digestate surface.

\section{Materials and Methods}

\subsection{Raw Materials}

The digestate used in this work was collected from a treatment plant located in Naples (South of Italy), processing the biodegradable fraction of municipal solid waste obtained from source-separated collection. The digestate was dried at $45^{\circ} \mathrm{C}$ until a constant weight. After obtaining the dried sample, a manual preselection was made by removing the coarsest material (branches, stones, roots, and so on) and then a 200 mesh $(75 \mu \mathrm{m})$ sieve was used to collect ground digestate sample [29].

The preliminary results showed the absorbance increase in distilled water once in contact with the raw digestate, suggesting the release of optically active matter into the solution from the digestate solid, which might interfere with the experiments. The differences between washed and not washed digestate samples in terms of dye removal efficiency were compared in this study. 
In this study, half of the raw digestate was used directly for experiments that named as "not washed $(\mathrm{NW})$ " sample. The other half was instead used to obtain the washed digestate (W); the purpose of the experiment was comparing the adsorption capacities and removal rates in both cases. The washing of the digestate was carried out with distilled water in a ratio of 1:25 $(\mathrm{g} / \mathrm{mL})$ for a time of approximately $24 \mathrm{~h}$ in order to remove released organic matter $[27,28]$. After this time, appropriate filtration and re-drying were carried out.

\subsection{Batch Adsorption Experiments}

The experiments were studied on two colorants belonging to the category of reactive dyes, one to the category of direct dyes, one to the category of acids, and one to the category of bases: Reactive Black 5, Reactive Violet 5 (Remazol Brilliant Violet 5R), Direct Yellow 27, Red 66 acid (Ponceau BS), and Methylene Blue (Basic Blue 9). The dyes used in the adsorption experiments were purchased from Sigma-Aldrich (St. Louis, MO, USA) and the molecular structure and properties of each dye are shown in Figure 1 [30-33]. The simulated dye solution was prepared to an initial concentration of $50 \mathrm{mg} / \mathrm{L}$ based on the recent studies involving dye adsorption [13-15].

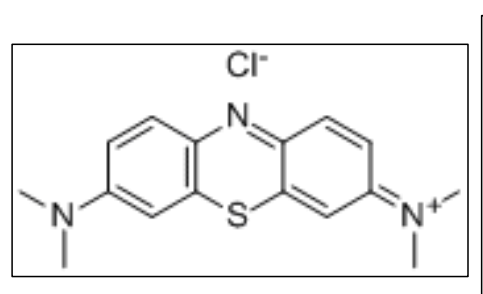

Methylene Blue

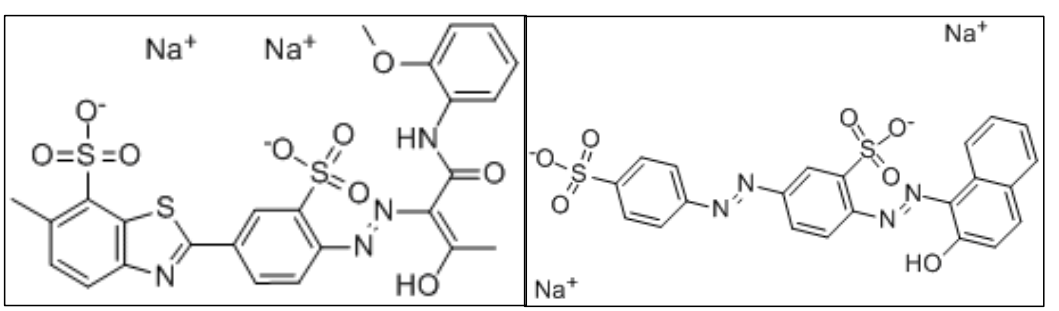

Direct Yellow 27

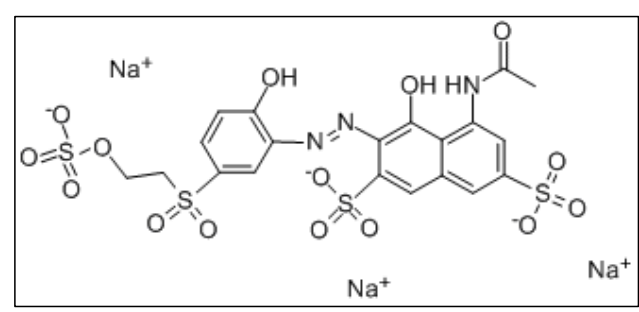

Reactive Violet 5

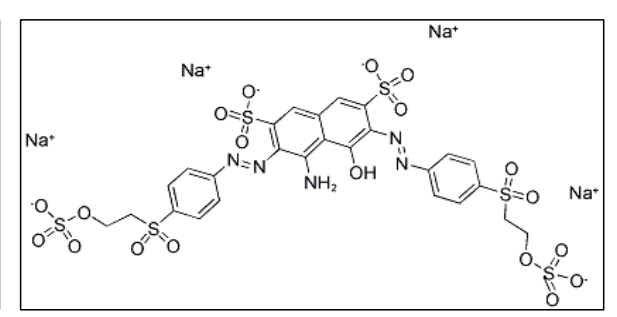

Reactive Black 5

Figure 1. Various dyes molecular structures.

Artificial dye solutions were mixed at different ratios of the digestate and colorant solution $(1: 1,1: 5,1: 10,1: 12.5,1: 25$, and 1:50 for DY27, AR66, RV5, and RB5, respectively, and 1:25, 1:50, 1:100, and 1:200 for MB). The mixed samples were placed into a thermostatic oscillator at a speed of $120 \mathrm{rpm}$, and sampling was carried out at 1, 2, 3, 4, 8, 24, and $48 \mathrm{~h}$ of treatment. In order to measure the dye concentrations, collected samples were analyzed through ultra-violet-visible spectrophotometer under different wavelengths ( $665 \mathrm{~nm}$ for MB, $595 \mathrm{~nm}$ for RB5, $577 \mathrm{~nm}$ for RV5, $507 \mathrm{~nm}$ for AR66, and $393 \mathrm{~nm}$ for DY27) depending on the dyes $\lambda_{\max }$ obtained from previous studies [34,35].

The mass of adsorbed dye per unit mass of digestate was obtained using the following mass balance equation [36]:

$$
q_{e}=\frac{\left(C_{0}-C_{e}\right) V}{m}
$$

where $C_{0}(\mathrm{mg} / \mathrm{L})$ is the dyes' initial concentration and $C e(\mathrm{mg} / \mathrm{L})$ is the dyes' concentration at equilibrium. $V(\mathrm{~L})$ is the solution volume, and $m(\mathrm{~g})$ is the dry adsorbent mass. All of the batch experiments were conducted in triplicate and the results were reported as average values with their standard errors. 


\subsection{Kinetic Models}

The adsorption kinetic and isotherm models were used to indicate the interaction between the adsorbent and the adsorbate when the adsorption process reaches the equilibrium time.

Kinetic studies are generally carried out to determine the adsorption rate of the adsorbates and control the equilibrium time of the entire adsorption process. In this study, the pseudo-first-order, pseudo-second-order, and intra-particle diffusion were selected for model fitting with experimental data.

On the basis of the adsorption capacity at different time intervals, the pseudo-first-order model is widely used in the adsorption of liquid adsorbates by solid adsorbents and is generally expressed as Equation (2) [37]:

$$
\frac{d q}{d t}=k_{1}\left(q_{e}-q\right)
$$

Integration of Equation (2) with the boundary conditions: $t=0, q=0$, and at $t=t, q=q$, gives

$$
\ln \left(q_{e}-q_{t}\right)=\ln q_{e}-k_{1} t
$$

where $q_{e}(\mathrm{mg} / \mathrm{g})$ is the adsorption capacity at equilibrium and $q t(\mathrm{mg} / \mathrm{g})$ is the adsorption capacity at time $t(\mathrm{~h})$, and $k_{1}(1 / \mathrm{h})$ is the rate constant of pseudo-first-order adsorption model. The values of $k_{1}$ and $q_{e}$ can be obtained from linear plot of $\ln \left(q_{e}-q_{t}\right)$ versus $t$.

The pseudo-second-order kinetic model based on equilibrium adsorption can be represented in Equation (4) [38]:

$$
\frac{d q}{d t}=k_{2}\left(q_{e}-q\right)^{2}
$$

Integration of Equation (4) with the boundary conditions $t=0, q=0$, and at $t=t, q=q$, resulted in

$$
\frac{1}{q_{e}-q_{t}}=\frac{1}{q_{e}}+k_{2} t
$$

where $k_{2}(\mathrm{~g} / \mathrm{mg} \cdot \mathrm{h})$ is the rate constant of the second-order adsorption. The values of $q_{e}$ and $k_{2}$ are calculated from the linear plot of $t / q t$ versus $t$.

The intra-particle diffusion model is generally expressed as Equation (6):

$$
q_{t}=k_{p} t^{1 / 2}+C
$$

where $k_{p}\left[\mathrm{mg} /\left(\mathrm{g} \cdot \mathrm{min}^{1 / 2}\right)\right]$ is the adsorption rate constant for the intra-particle model.

Normalized standard deviation parameter $\Delta q(\%)$ was also used to validate the standard errors between pseudo first and second models by the following equation:

$$
\Delta q_{t}(\%)=100 \sqrt{\frac{\sum\left[\left(q_{t, \mathrm{exp}}-q_{t, \mathrm{cal}}\right) / q_{t, \mathrm{cal}}\right]^{2}}{(N-1)}}
$$

where $N$ is the number of experimental data, and $q_{t, \exp }$ and $q_{t, \mathrm{cal}}$ are the experimental adsorption capacity and the calculated adsorption capacity $(\mathrm{mg} / \mathrm{g})$, respectively. It is clear that the lower values of this parameter show a better fitting of experimental and calculated data [39].

\subsection{Isotherm Models}

The adsorption isotherm indicates how the adsorbate molecules are distributed between the liquid adsorbate and the solid adsorbent at given $\mathrm{pH}$ values and temperatures.

The adsorption capacity of an adsorbent can be determined by its equilibrium adsorption isotherm, which can explain the amount of adsorbed substance when the adsorption reaches a dynamic equilibrium. To analyze the validity of the adsorption data, experimental results at equilibrium time were fitted to Langmuir, Freundlich, and Sips adsorption isotherm models. 
The Langmuir model is based on the following assumptions, the adsorbent has a uniform adsorption surface, there is no interaction force between adsorbent molecules, and there is no substance transfer on the adsorbent surface. The monolayer adsorption model can be represented as the following linear Equation (8) [40]:

$$
\frac{C_{e}}{q_{e}}=\frac{1}{K_{L} q_{m}}+\frac{C_{e}}{q_{m}}
$$

where $C_{e}(\mathrm{mg} / \mathrm{L})$ is the equilibrium concentration of metal ions, $q_{e}(\mathrm{mg} / \mathrm{g})$ is the amount of metal ions adsorbed onto the adsorbent material at the equilibrium, $q_{m}(\mathrm{mg} / \mathrm{g})$ is the theoretical maximum adsorption capacity of metal ions onto the adsorbent, and $K_{L}(\mathrm{~L} / \mathrm{mg})$ is the Langmuir adsorption equilibrium constant.

The Freundlich isotherm equation describes a multilayer adsorption owing to the interaction between adsorbed molecules onto heterogeneous surfaces and is described by Equation (9) [41]:

$$
q_{e}=K_{F} C_{e}^{1 / n}
$$

where $K_{F}\left((\mathrm{mg} / \mathrm{g})(\mathrm{L} / \mathrm{mg})^{1 / n}\right)$ and $n$ are the Freundlich adsorption isotherm constants, which are indicators of adsorption capacity and adsorption intensity, respectively.

The combination of the Freundlich and Langmuir gave the Sips model Equation (10) [34].

$$
q_{e}=\frac{K_{L F} q_{m} C_{e}^{n}}{1+K_{L F} C_{e}^{n}}
$$

where $K_{L F}$ is the adsorption constant of Sips (L/mg). At low dye concentrations, this model reduces to the Freundlich isotherm; while at high concentrations, it characterizes a Langmuir type isotherm. When the heterogeneity factor is 1 , the model assumes the Langmuir model, and when $n>1$, positive cooperativity is assumed, while when $0<n<1$, negative adsorption cooperativity is expected.

\section{Results and Discussion}

\subsection{Adsorption Ratio and Adsorption Capacity}

Figure 2 shows for each experimental condition that the dye adsorption increased rapidly with time from 1 to $4 \mathrm{~h}$ and then slowed down until it plateaued before $48 \mathrm{~h}$. MB achieved the highest dye adsorption capacity at ratio 1:200 (105.59 mg/g), followed by RV5 at ratio 1:50 (24.42 mg/g), RB5 at ratio 1:50 (20.35 mg/g), DY27 at ratio 1:50 (18.86 mg/g), and AR66 at ratio 1:50 (17.03 mg/g). It can be seen that more than $90 \%$ of the total adsorbed dyes occurred before $24 \mathrm{~h}$ for DY27, RV5, RB5, and AR66. It can be hypothesized that the dye adsorption phenomena through the involved digestate could be composed of the following steps: (i) the first initial and rapid colorants adsorption in the first $2 \mathrm{~h} 44 \mathrm{~h}$ of the reaction; (ii) the removal rate rapid increase, probably owing to the abundantly accessible sites on the adsorbent surface at the initial stage of the reaction; and (iii) the dye molecules fast combination with the active sites on the adsorbent [42]. When the surface active sites were exhausted, the adsorption rate slowed down. During this period, the adsorption rate was controlled by the transmission rate from the surface of the adsorbent to the pore structure inside the adsorbent, until equilibrium was reached at $4 \mathrm{~h}$ for MB and AR66, while for DY27, RV5, and RB5, the equilibrium time lasted longer ( $8 \mathrm{~h} 24 \mathrm{~h})$.

It can be seen from Figure 2 that, with a higher dosage of adsorbent, a higher adsorption capacity was obtained, only owing to the providing of higher active sites. It is obvious that, with the increase of the amount of adsorbent, the active sites of the adsorbent also increase. Therefore, under the high adsorbent dosage, the number of active sites is greater than the dye molecules, which leads to the possibility that a considerable proportion of the active sites on the adsorbents have no effect, resulting in a decrease in the actual efficiency of the adsorption [43]. 


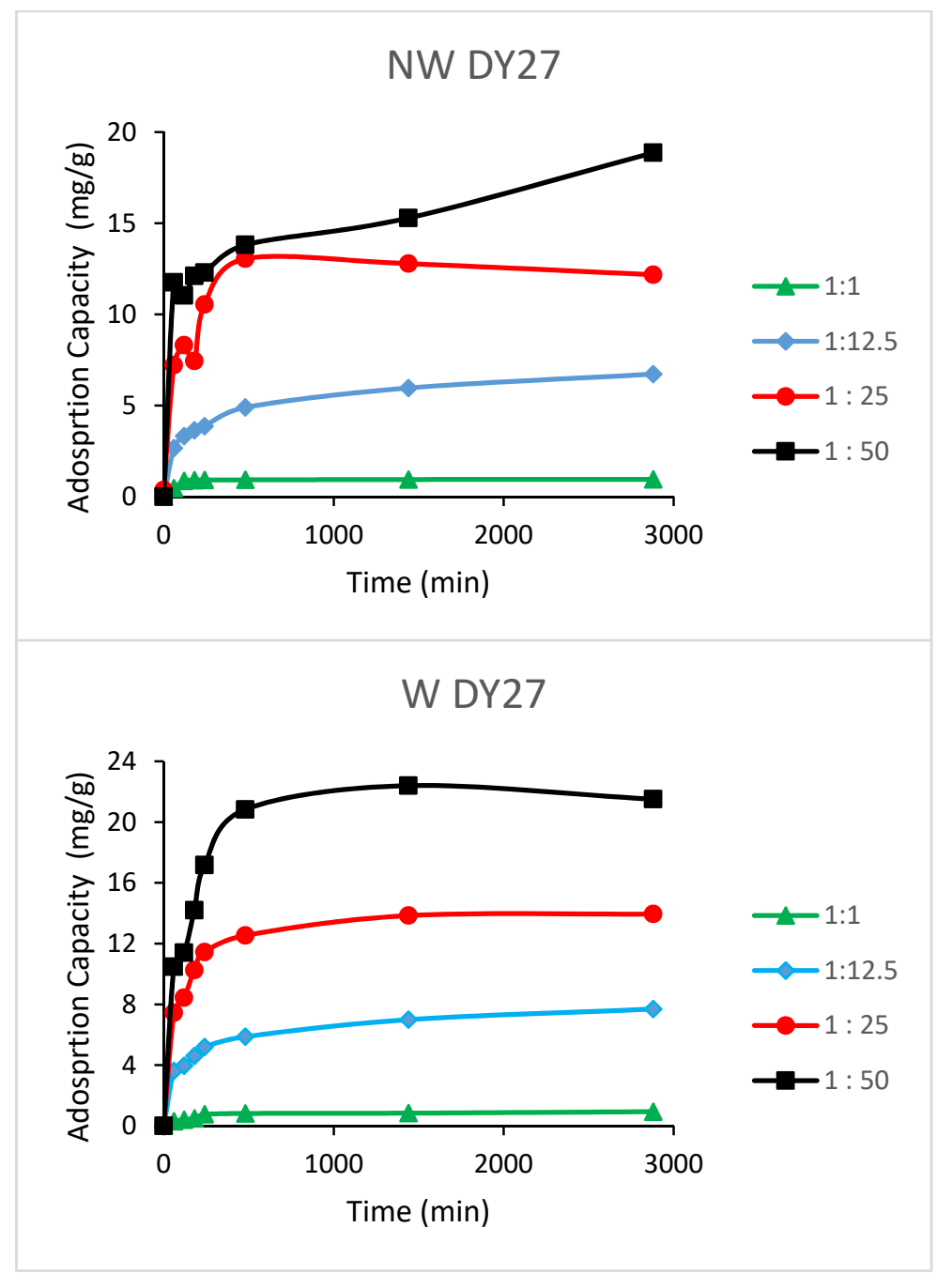

(a)

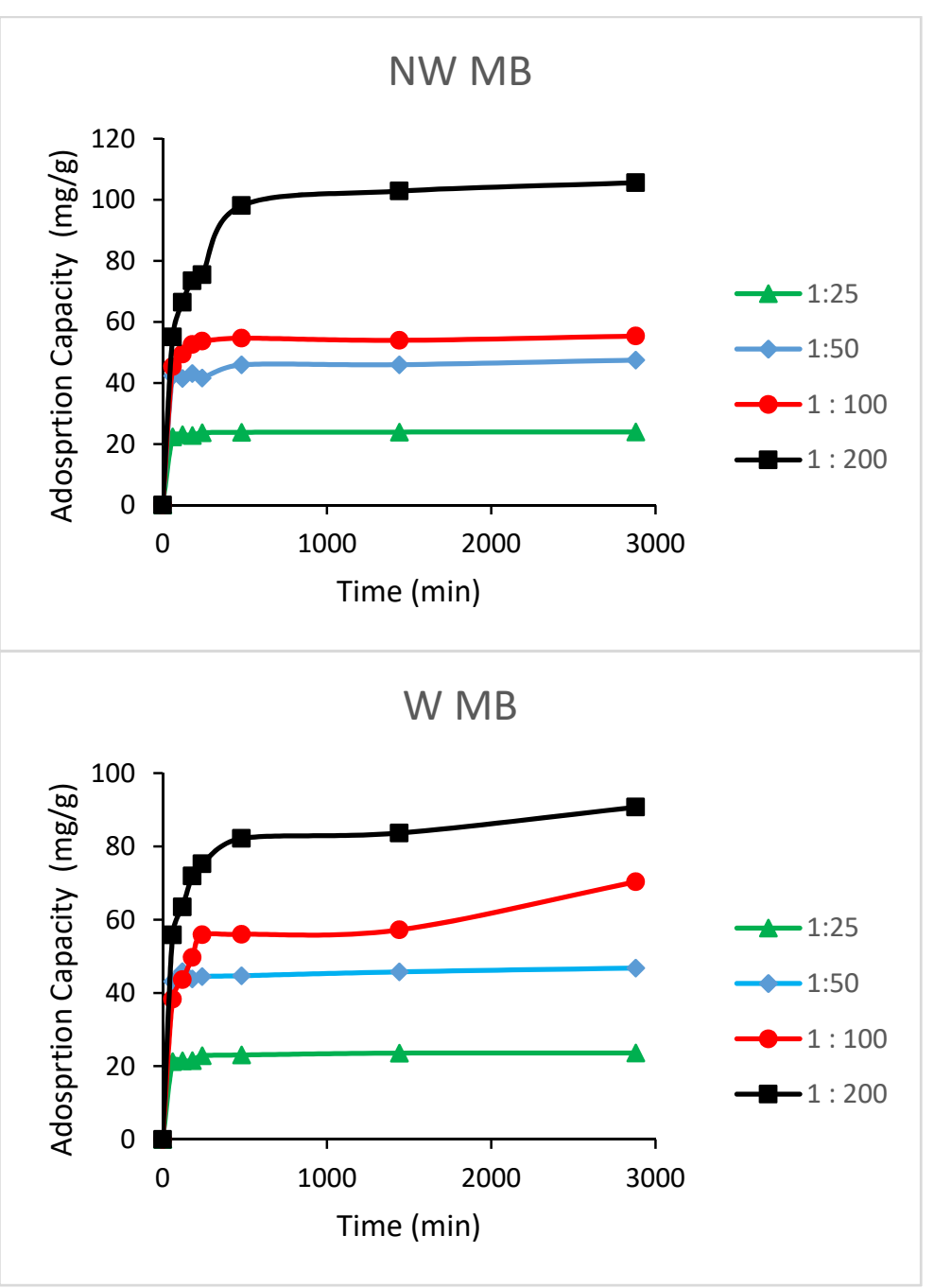

(b)

Figure 2. Cont. 


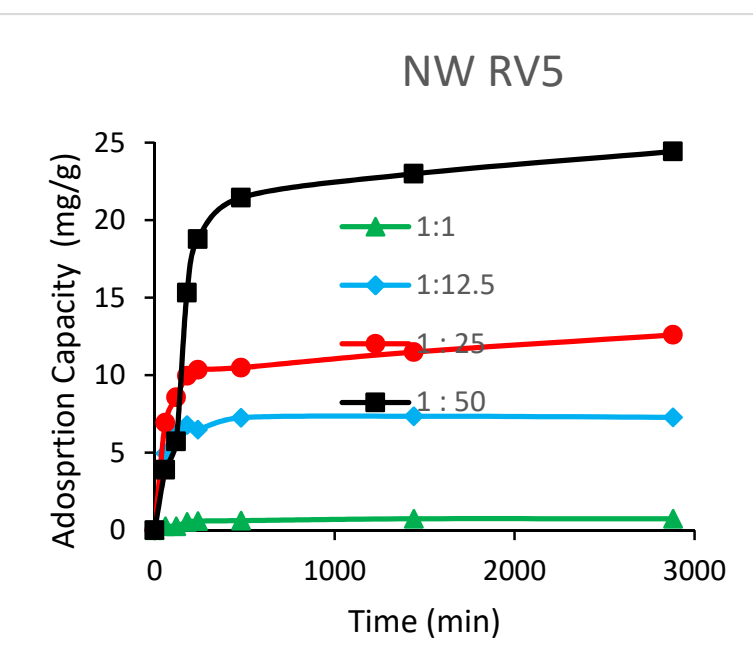

W RV5

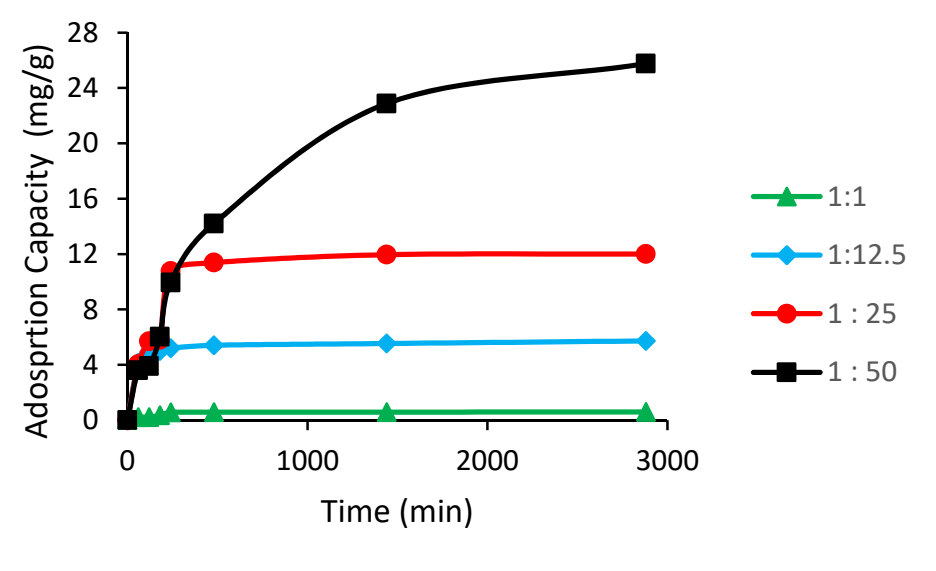

(c)
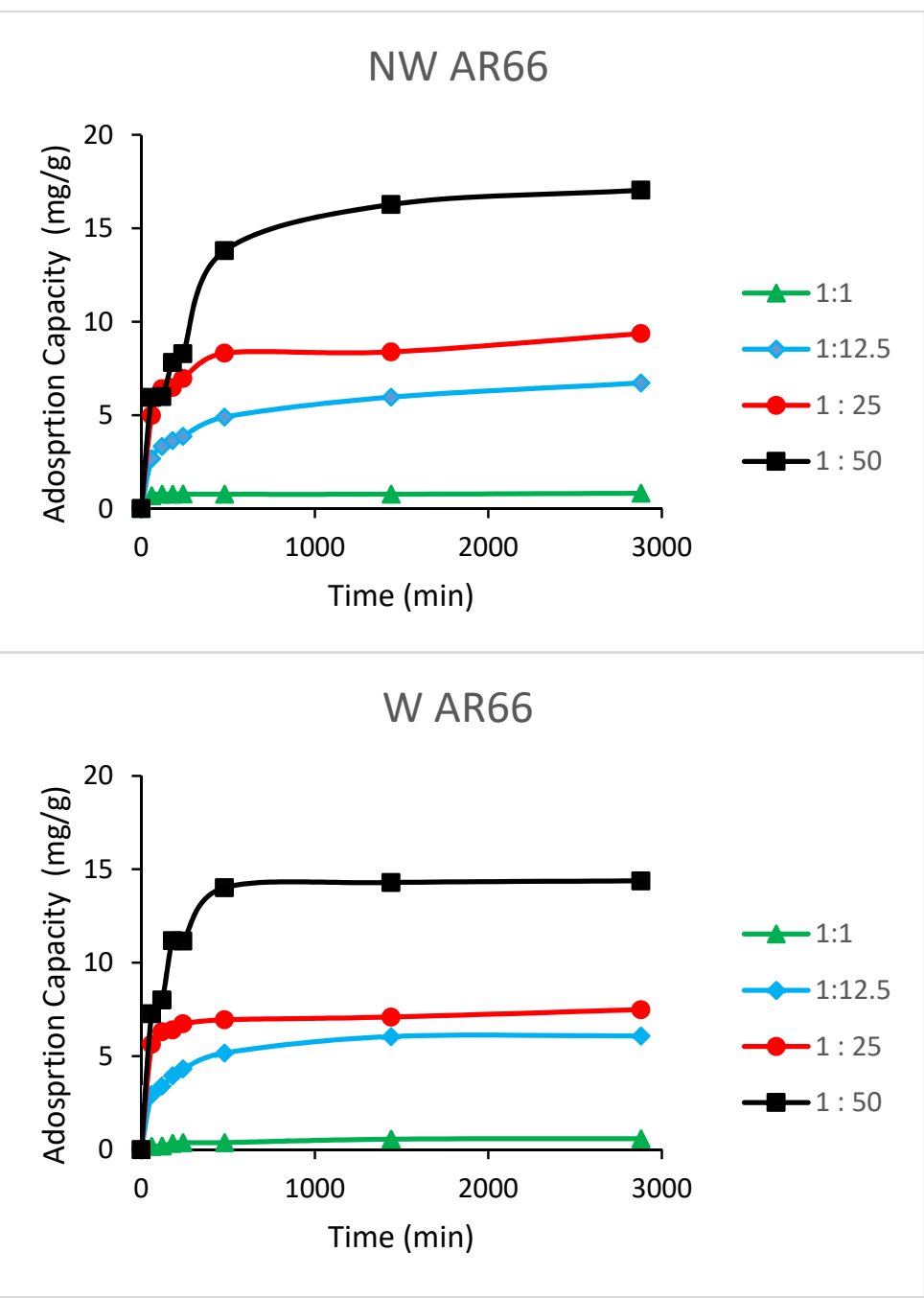

(d)

Figure 2. Cont. 


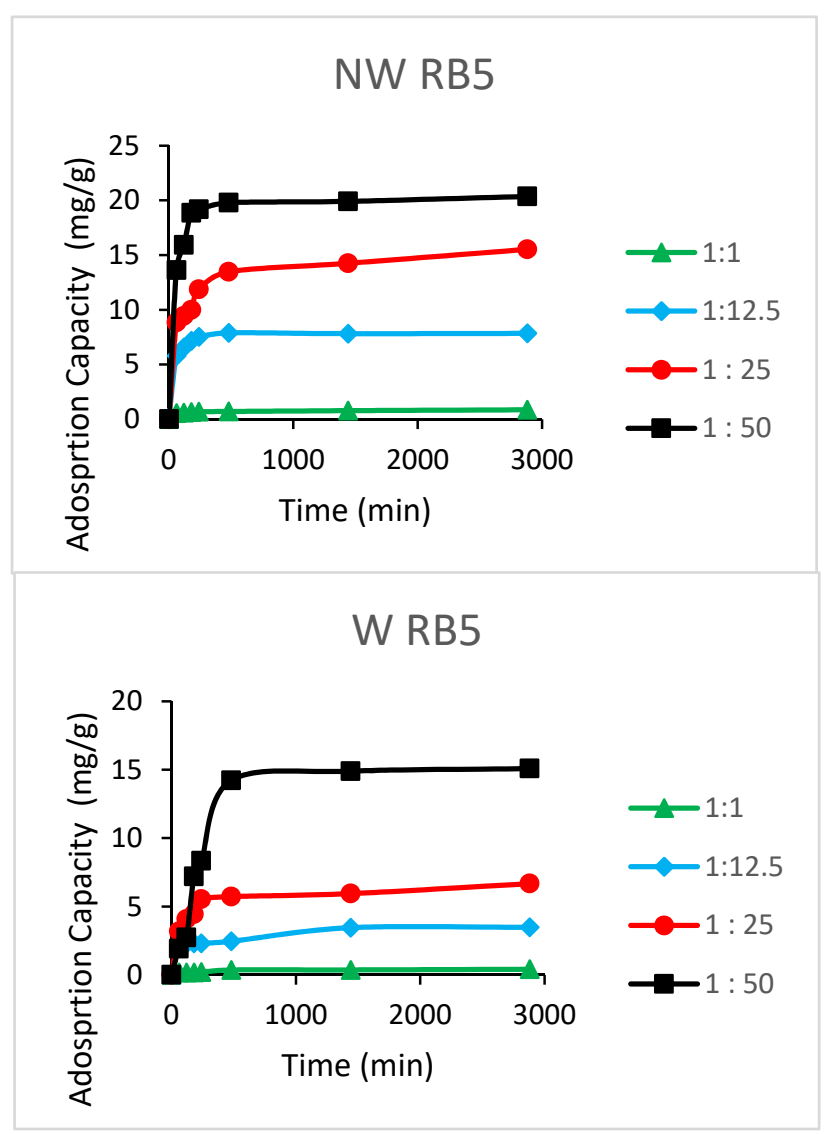

(e)

Figure 2. Effect of ratios on adsorption capacity by not washed (NW) and washed (W) digestate adsorbents towards various dyes removal. Ratios: $\left(\mathrm{W}_{\text {adsorbents }}\right.$ (g): $\mathrm{C}_{\text {dyes }}(\mathrm{mg} / \mathrm{L})$ ). (a) Methylene Blue (MB); (b) Direct yellow 27 (DY27); (c) Acid Red 66 (AR66); (d) Reactive Violet 5 (RV5); (e) Reactive Black 5 (RB5). 
During this stage, dye molecules can quickly bind to active sites in the adsorbent, when the active sites in the adsorbent are almost occupied, the reaction rate decreases, reflected in the increase of the removal rate afterwards, which tends to be gentle. The reaction rate is dominated by the mass transfer rate into and out of the sorbent until the adsorption reach equilibrium. Compared with the results of the previous research data $[44,45]$, it can be found that the digestate adsorbent used in this study had efficient adsorption efficiency. Under the same dosage or adsorption time, the adsorbent could obtain higher dye adsorption capacity, while other adsorbents required more dosage or longer adsorption time to achieve the desired result.

From Figure 2, by comparing the data from not washed and washed digestate on dye adsorption, it was possible to observe that the higher release values mostly occurred by involving the NW digestate. Moreover, not washed digestate sample was also the one characterized by a higher removal rate toward dyes. This may prove that the washing process of digestate enhanced the release of dissolved organic matter from the solid material and these particles may be organic matter, which plays a significant role in dye adsorption and removal. Furthermore, owing to the low removal achieved with the washed digestate adsorbent, it was assumed that considerable fractions of the contaminants were likely to adsorb on colloids removed from the digested by washing [46]. Under the same operating conditions, the optimal value of not washed digestate adsorbent dosage could be useful in order to obtain considerable dye removal efficiency as well as to decrease resources' consumption rate and treatment costs compared with the washed digestate [47].

Figure 3 shows the adsorption capacity data of the various dyes onto digestate sample. All the dye adsorption reactions reached equilibrium quickly after $4 \mathrm{~h}$. This may owe to reduced external and internal mass transport resistances. Proper stirring speed and possibly considerable pore structure could provide a constant and stable reaction environment [48]. Among them, the adsorption effect of MB was particularly obvious, which may be caused by the size of dye molecules [49]. According to the summarization of the physical and chemical properties of each dye, the molecular size of MB (MW $=319 \mathrm{mg} / \mathrm{mol}$ ) was found to be smaller compared with the other four dye molecules. This may indicate that the pore structure of the adsorbent is more inclined to the meso and microporous structure, which has a bias for the adsorption of dye molecules with smaller particle sizes. In addition, this result may also indicate that some chemical adsorption processes occurred more often between $\mathrm{MB}$ and the adsorbents, and the reaction between $\mathrm{MB}$ molecules and specific functional groups on the surface of the adsorbent is stronger and more frequent [50]. In this case, further experiments should be considered to investigate the removal of similar molecule size pollutants with MB. Detailed characterization measurement of digestate adsorbents should be investigated in order to understand the adsorption mechanism.

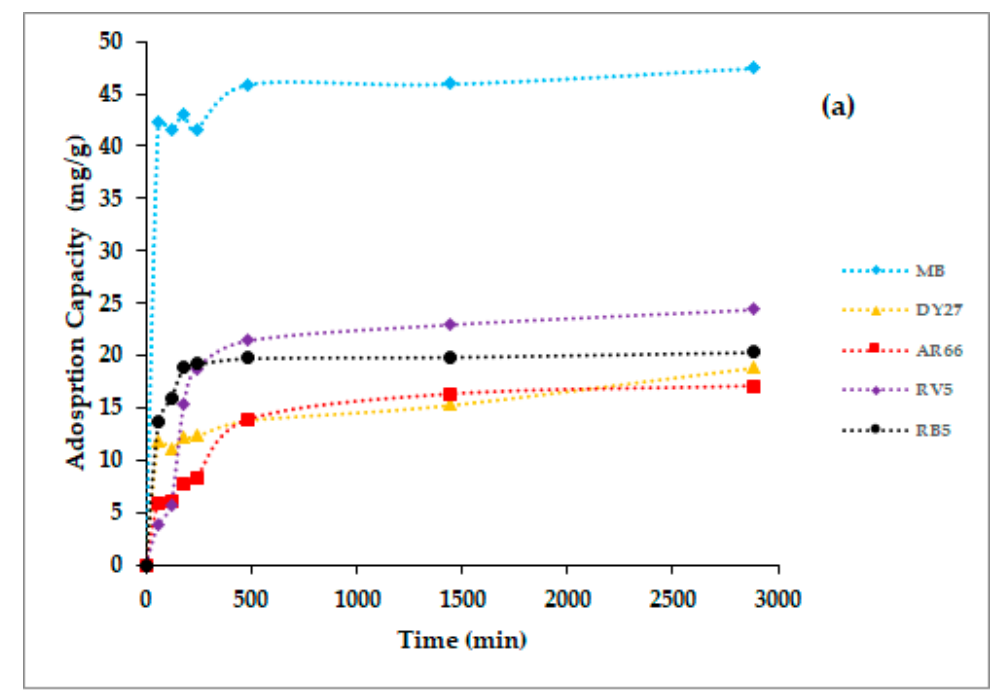

Figure 3. Cont. 


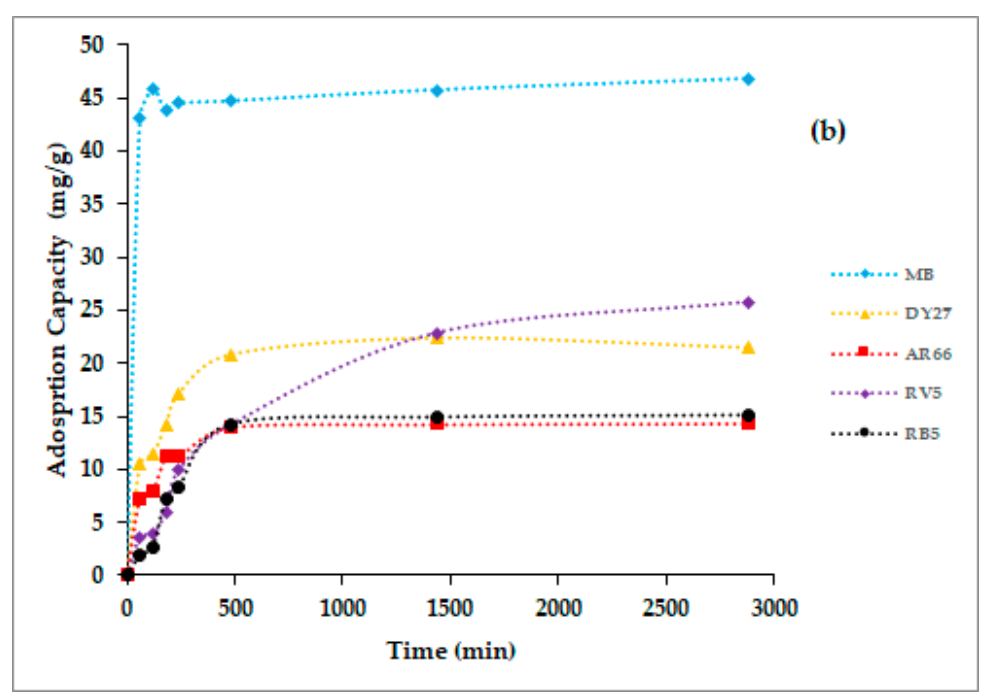

Figure 3. Adsorption capacity of various dyes onto digestate adsorbents. Ratio 1:50 ( $\mathrm{W}_{\text {adsorbents }}=0.05 \mathrm{~g}$ : Cdyes $=50 \mathrm{mg} / \mathrm{L}$ ). (a) Not washed digestate adsorbent, (b) washed digestate adsorbent.

Similarly, it can also be found from Figure 3 that, for every dye, the adsorption capacity of the NW adsorbent was higher than the washed adsorbent. However, the trend of adsorption behavior towards different dye types was similar. Finally, the significant adsorption rate on MB was still observable in the washed adsorbent results.

\subsection{Initial Dye $\mathrm{pH}$ and Concentrations}

The research investigated digestate adsorption at different $\mathrm{pH}$ conditions $(\mathrm{pH}=3$ to 8$)$ for all the dye solutions. The removal rates and adsorption capacities after $48 \mathrm{~h}$ remained similar at all $\mathrm{pH}$ conditions, and the $\mathrm{pH}$ value before and after the adsorption only shifted slightly. Therefore, it can be explained that the $\mathrm{pH}$ may have an insignificant influence during the adsorption process between digestate and dyes.

Deng, et al. [1] used cotton stalk (CS), sulphuric acid treated cotton stalk (SCS), and phosphoric acid treated cotton stalk (PCS) as adsorbents for removing Methylene Blue (MB) from aqueous solutions, and the adsorption capacity was in the order of SCS > PCS > CS. It was identified that initial $\mathrm{pH}$ of aqueous solution had a great impact on the removal efficiency of CS. However, further treatment to the cotton stalk adsorbents increased the economic cost and phosphoric acid addition may cause a eutrophication effect on the aquatic environment.

Gök, et al. [2] investigated the removal of Reactive Blue 19 (RB19) onto modified bentonite from aqueous solutions. The optimum $\mathrm{pH}$ value for the adsorption experiments was found to be 1.5 and all the experiments were carried out at this $\mathrm{pH}$ value. The acidity requirement was considered too low and it was difficult to implement in practical application. In addition, the low $\mathrm{pH}$ value required high concentration acid addition, which led to excess economic consumption.

However, in this research, the impact of initial $\mathrm{pH}$ of dye solution was negligible, which demonstrated good adaptability of digestate under different $\mathrm{pH}$ conditions compared with the studies mentioned above. There were no additives required to adjust the $\mathrm{pH}$ of the solution. Thus, the optimum $\mathrm{pH}$ value for digestate removal on dyes is the initial solution $\mathrm{pH}$.

The influence of the dye initial concentration in the solutions on the digestate adsorption rate was investigated at the initial $\mathrm{pH}$ value $\left(\mathrm{pH}_{\mathrm{RB} 5}=6.58, \mathrm{pH}_{\mathrm{AR} 66}=6.48, \mathrm{pH}_{\mathrm{DY} 27}=7.01, \mathrm{pH}_{\mathrm{RV} 5}=6.80\right.$, $\mathrm{pH}_{\mathrm{MB}}=6.89$ ). As shown in Figure 4, when the initial dye concentration increased, the digestate adsorption capacity increased as well. This indicated that the initial dye concentration could strongly affect the adsorption capacities of dye onto digestate. The adsorption process reached equilibrium quickly at a lower concentration. Under a specific amount of adsorbent, the adsorption surface area and related available active sites are limited [51]. Even if, at a high concentration, dye molecules 
increase and drive the adsorbate particles closer to the adsorbent particles, it is still difficult for the saturated adsorbent to adsorb the excess adsorbate because all the active sites have been occupied. In addition, the involved driving force is the mass gradient, which increases with an increase in initial dye concentration [52]. At lower concentrations, the ratios of adsorbates to the adsorption sites are low and higher presence of only monolayer coverage occurs. On the contrary, multilayer adsorption is more likely to happen at a higher concentration.

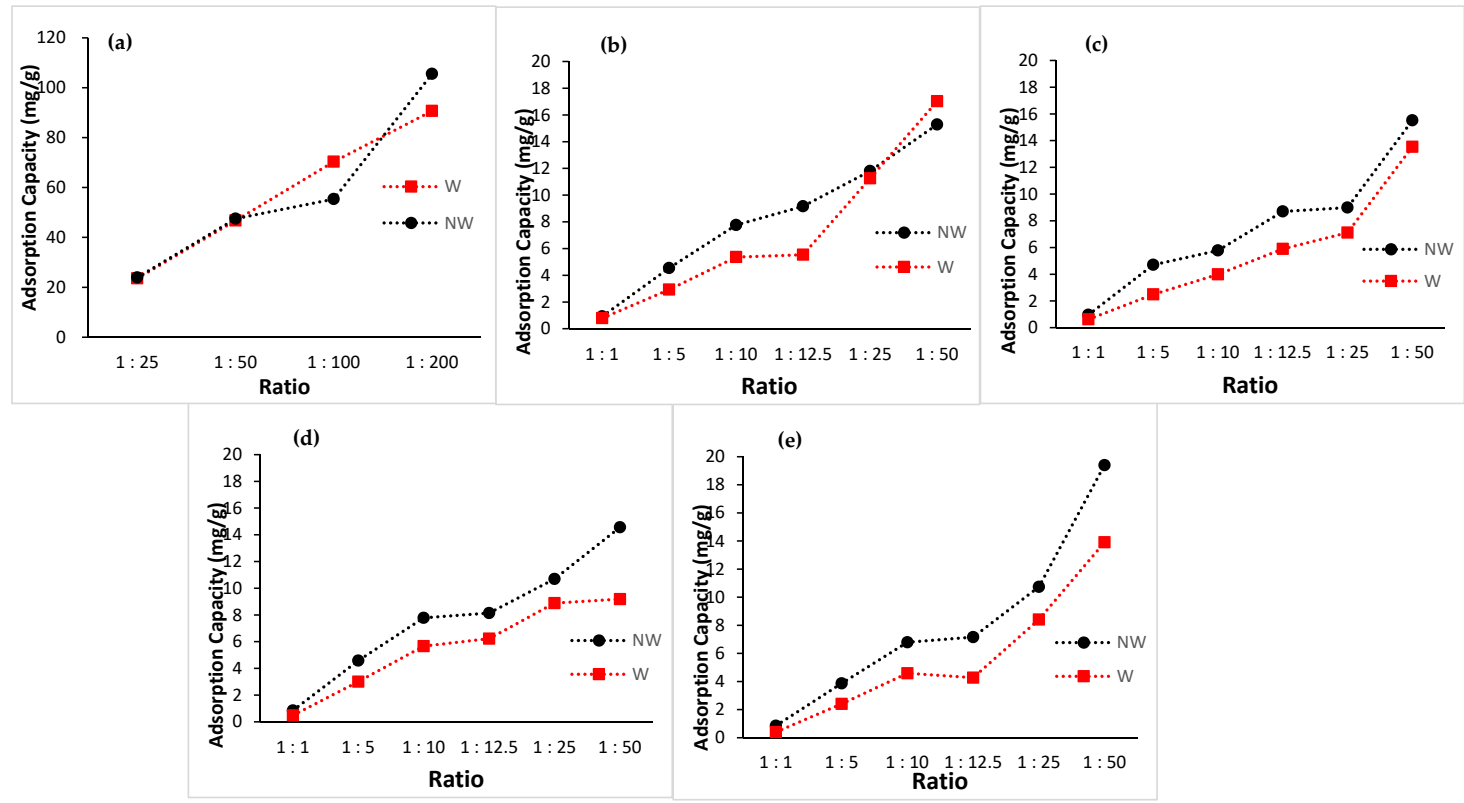

Figure 4. Adsorption capacity under different ratio at $48 \mathrm{~h}$ for not washed and washed digestate adsorbent removal of various dyes. (a) MB; (b) DY27; (c) AR66; (d) RV5; (e) RB5.

\subsection{Adsorption Kinetics}

As shown in Table 1, the highest correlation coefficients were obtained from the application of the pseudo-second order kinetic model, thus demonstrating that this model provided a suitable fit between calculated and experimental data. According to this, it was possible to assess that both the dye concentrations and the adsorbents used in the adsorption process were involved in the speed determination phase [53]. According to Table 1, the $k_{2}$ calculated from pseudo-second order model represented the adsorption rate of the reaction, and the values at high ratios were relatively higher than other ratios. These results confirmed the assumption in the batch experiment results. With higher dosage of the adsorbents, more active sites were added into the adsorption system, which provided more space with which adsorbates to be occupied. As a matter of fact, this also increased the adsorption rate during each dye removal reaction. The applicability of the pseudo-second order kinetic model demonstrated that the limiting stage of the process was the adsorptive mechanism rather than the mass transfer from the solution to the adsorbent's surface. It also reflected that the adsorption behavior may involve the valence forces through sharing electrons between the adsorbate and adsorbents [54].

Similar results were also found out by Berrazoum, et al. [10], who acquired biosorbent obtained from municipal solid waste for the sorption of yellow procion reactive dye MX-3R. The results clearly showed that the adsorption kinetic mechanism of MX-3R onto biosorbent followed the pseudo second-order model.

Zhou, et al. [12] also found out the biggest $\mathrm{R}^{2}$ value from fitted pseudo-second-order kinetics model based on the adsorption removal study of cationic red X-5GN and cationic blue X-GRRL using industrial waste coal gangue. 
Table 1. Kinetic parameters of different models for various dyes adsorption on the not washed (NW) and washed $(\mathrm{W})$ digestate adsorbent. MB, Methylene Blue.

\begin{tabular}{|c|c|c|c|c|c|c|c|c|c|c|c|}
\hline \multirow[b]{2}{*}{ Adsorbents } & \multirow[b]{2}{*}{$\begin{array}{l}q_{e(\exp )} \\
(\mathrm{mg} / \mathrm{g})\end{array}$} & \multicolumn{4}{|c|}{ Pseudo-First-Order } & \multicolumn{4}{|c|}{ Pseudo-Second-Order } & \multicolumn{2}{|c|}{ Intra-Particle Diffusion } \\
\hline & & $\begin{array}{c}q_{e(\mathrm{cal})} \\
(\mathrm{mg} / \mathrm{g})\end{array}$ & $\begin{array}{c}k_{1} \\
(1 / \mathrm{h})\end{array}$ & $\mathbf{R}_{1}^{2}$ & $\begin{array}{c}\Delta q \\
(\%)\end{array}$ & $\begin{array}{c}q_{e(\mathrm{cal})} \\
(\mathrm{mg} / \mathrm{g})\end{array}$ & $\begin{array}{c}k_{2} \\
(\mathrm{~g} / \mathrm{mg} \cdot \mathrm{h})\end{array}$ & $\mathbf{R}^{2}$ & $\begin{array}{c}\Delta q \\
(\%)\end{array}$ & $\begin{array}{c}k_{p} \\
{\left[\mathrm{mg} /\left(\mathrm{g} \cdot \min ^{1 / 2}\right)\right]}\end{array}$ & $\mathbf{R}_{3}{ }^{2}$ \\
\hline MB nw 1:200 & 102.85 & 105.59 & 0.0023 & 0.8542 & 1.5381 & 107.53 & 0.0002 & 0.9991 & 2.6254 & 1.0334 & 0.7735 \\
\hline Yellow nw 1:50 & 18.86 & 20.00 & 0.0007 & 0.8225 & 3.4722 & 18.51 & 0.0005 & 0.9780 & 1.0617 & 0.1448 & 0.8413 \\
\hline Red nw 1: 50 & 16.27 & 17.03 & 0.0010 & 0.7534 & 2.6969 & 17.98 & 0.0003 & 0.9924 & 6.0879 & 0.2657 & 0.8542 \\
\hline Violet nw 1: 50 & 24.42 & 24.50 & 0.0019 & 0.9410 & 0.1757 & 26.04 & 0.0002 & 0.9812 & 3.8198 & 0.385 & 0.6118 \\
\hline Black nw 1:50 & 20.35 & 19.90 & 0.0020 & 0.5324 & 1.2735 & 20.44 & 0.0024 & 0.9998 & 0.2655 & 0.1026 & 0.4749 \\
\hline MB w 1:200 & 83.65 & 90.70 & 0.0013 & 0.5654 & 4.8645 & 90.91 & 0.0002 & 0.9986 & 5.0102 & 0.6282 & 0.7565 \\
\hline Yellow w 1:50 & 22.40 & 21.50 & 0.0010 & 0.6288 & 2.3115 & 22.88 & 0.0006 & 0.9986 & 1.2432 & 0.2492 & 0.7202 \\
\hline Red w 1: 50 & 14.37 & 14.28 & 0.0034 & 0.8608 & 0.3614 & 14.66 & 0.0013 & 0.9990 & 1.1365 & 0.1416 & 0.6430 \\
\hline Violet w 1: 50 & 25.75 & 25.80 & 0.0021 & 0.9765 & 0.0993 & 29.94 & 0.0001 & 0.9470 & 9.3800 & 0.5205 & 0.9398 \\
\hline Black w 1:50 & 15.08 & 15.10 & 0.0023 & 0.9322 & 0.0747 & 16.80 & 0.0002 & 0.9619 & 6.6088 & 0.2807 & 0.6947 \\
\hline
\end{tabular}

\subsection{Adsorption Isotherms}

As shown in Table 2, better data fitting can be observed with the Langmuir isotherm model with higher correlation coefficients compared with the Freundlich and Sips model for most of the colorants. In addition, the highest $R^{2}$ value was obtained from Methylene Blue, whose adsorption capacity was also better interpreted by the Langmuir model.

Table 2. Isotherm parameters of different models for various dyes adsorption on the not washed (nw) and washed $(\mathrm{w})$ digestate adsorbent.

\begin{tabular}{|c|c|c|c|c|c|c|c|c|c|c|c|c|}
\hline \multirow[b]{2}{*}{ Dye } & \multirow{2}{*}{$\begin{array}{c}q_{e} \\
(\mathrm{mg} / \mathrm{g})\end{array}$} & \multicolumn{4}{|c|}{ Langmuir Isotherm } & \multicolumn{3}{|c|}{ Freundlich Isotherm } & \multicolumn{4}{|c|}{ Sips Isotherm } \\
\hline & & $\begin{array}{c}q_{m} \\
(\mathrm{mg} / \mathrm{g})\end{array}$ & $\begin{array}{c}K_{L} \\
(\mathrm{~L} / \mathrm{mg})\end{array}$ & $R_{L}$ & $\mathbf{R}^{2}$ & $\begin{array}{c}K_{F} \\
\left(\mathrm{mg} / \mathrm{g}(\mathrm{L} / \mathrm{mg})^{1 / n}\right)\end{array}$ & $\begin{array}{c}1 / n \\
(\mathrm{mmol} / \mathrm{g})\end{array}$ & $\mathbf{R}^{2}$ & $\mathbf{n}$ & $\begin{array}{c}q_{m} \\
(\mathrm{mg} / \mathrm{g})\end{array}$ & $\begin{array}{c}K_{L F} \\
(\mathrm{~L} / \mathrm{mg})\end{array}$ & $\mathbf{R}^{2}$ \\
\hline Yellow W & 17.0318 & 1.8850 & 0.0289 & 0.4088 & 0.8905 & 1.8055 & 0.9870 & 0.7801 & 1.0132 & 1.9968 & 0.0273 & 0.9032 \\
\hline Black NW & 19.4047 & 5.5402 & 0.0262 & 0.4331 & 0.5105 & 29.3833 & 1.8085 & 0.9234 & 0.5529 & 5.6022 & 0.1093 & 0.7886 \\
\hline Black W & 16.8394 & 0.8210 & 0.0215 & 0.4814 & 0.0506 & 19.9950 & 2.8271 & 0.1300 & 0.3537 & 1.2073 & 0.2309 & 0.1652 \\
\hline Violet NW & 14.5638 & 25.7069 & 0.0105 & 0.6568 & 0.0305 & 1.4292 & 1.4815 & 0.4285 & 1.2267 & 16.4474 & 0.0411 & 0.7575 \\
\hline Violet W & 9.1926 & 3.0497 & 0.0151 & 0.5703 & 0.0161 & 32.4190 & 0.8152 & 0.1231 & 0.6750 & 6.4977 & 0.0509 & 0.2682 \\
\hline MB NW & 105.5900 & 135.1351 & 0.1682 & 0.1063 & 0.9264 & 24.4118 & 1.9312 & 0.7240 & 0.5178 & 196.0784 & 0.2417 & 0.7715 \\
\hline MB W & 90.6980 & 116.2791 & 0.1203 & 0.1426 & 0.9465 & 19.6562 & 2.1299 & 0.8092 & 0.4695 & 188.6792 & 0.1834 & 0.9120 \\
\hline
\end{tabular}

The isotherm fitted with the Langmuir model also showed that the NW digestate adsorption could be a more representative adsorption process compared with the washed digestate, which had lower $\mathrm{R}^{2}$ values of all the colorants.

As mentioned above, the Freundlich model parameter $1 / n$ represented the heterogeneity factor, which can be used to evaluate whether the adsorption process was chemisorption (for $1 / n>1$ ) or physisorption (for $1 / n<1$ ) [55]. In the present work, this parameter displayed different values for washed and not washed adsorbents (Table 2). In fact, the adsorption process with washed digestate resulted physical, while the adsorption process by not washed digestate was chemical. This could suggest that the released DOM from digestate was the main affecting factor of the adsorption process because of the chemical reaction occurred with the dye molecules. After washing, the DOM was eliminated from the adsorbent, and the entire adsorption process was simply physical between the dye molecule and digestate. Langmuir model provided maximum monolayer adsorption capacity, which was obtained as $135.13 \mathrm{mg} / \mathrm{g}$ by not washed digestate adsorbent for MB removal. Furthermore, the dimensionless separation factor can be calculated from Langmuir model, which was described by Equation (8), is a valuable parameter to assess the adsorption process: process is irreversible if $R_{L}=0$, favorable if $0<R_{L}<1$, linear if $R_{L}=1$ [56].

$$
R_{L}=\frac{1}{1+K_{L} C_{0}}
$$


where $C_{0}$ refers to dye initial concentration $(\mathrm{mg} / \mathrm{L})$ and $K_{L}(\mathrm{~L} / \mathrm{mg})$ is Langmuir constant. This factor was easily calculated, and for all initial concentrations conducted in this work, the $R_{L}$ was between 0 and 1 (Table 2), indicating a favorable process. This result confirmed the previous assessment of adsorption process studied by $1 / n$ value in Freundlich model. The higher the $1 / n$ value, the more dominant the chemical adsorption reaction. At the same time, the lower the $R_{L}$ value, the closer the adsorption reaction is to irreversibility.

\section{Conclusions}

The use of the digestate as an innovative adsorbent material for dye removal was proved to be satisfactory.

Batch adsorption experiments were carried out towards various dyes (Methylene Blue, Direct yellow 27, Acid Red 66, Reactive Violet 5, Reactive Black 5) and the results showed that the dye adsorption rapidly increased up to $4 \mathrm{~h}$ and then slowed down until the achievement of the equilibrium condition before $48 \mathrm{~h}$ for all dyes. Highest dye adsorption capacity was observed for MB at ratio 1:200 $(105.59 \mathrm{mg} / \mathrm{g})$, followed by RV5 at a ratio of $1: 50(24.42 \mathrm{mg} / \mathrm{g})$, RB5 at a ratio of 1:50 $(20.35 \mathrm{mg} / \mathrm{g})$, DY27 at a ratio of 1:50 (18.86 mg/g), and AR66 at a ratio of 1:50 $(17.03 \mathrm{mg} / \mathrm{g})$.

From a comparison of washed and not washed samples, it appears that the adsorption process is more favourable for samples treated with not washed digestate than with washed one. From these two considerations, it can be assumed that part of the dye was adsorbed directly on the material that was released from the adsorbent after the washing. This perspective could be interesting as it might be the main reason of the adsorption mechanism. Therefore, further studies focusing on the DOM released from the digestate deserve deepened focus and discussion.

The study of kinetics has shown that the adsorption process depended on the concentrations of both adsorbents and adsorbates (pseudo-second order model). In this case, the mechanisms of chemical adsorption have produced very favorable removal efficiency results for DY27, AR66, RB5, $\mathrm{RV} 5$, and MB.

The isotherm fitted with the Langmuir model also showed that the adsorption with not washed digestate was more efficient than adsorption with the washed digestate, which was characterized by lower $\mathrm{R}^{2}$ values for all the colorants.

Finally, the results observed in this work could provide a better understanding on the adsorption behavior of the digestate and useful information on the beneficial utilization of this promising low-cost renewable source. It is valuable to investigate the reusability of the sorbents in order to demonstrate their efficiency in a number of cycles sorption/desorption in the future study. Further study should also include physicochemical analysis of the digestate particles before and after adsorption in order to deeply understand the digestate adsorption process.

Author Contributions: Conceptualization, M.F. and Y.C.; Data curation, S.Y. and O.A.; Formal analysis, S.Y. and O.A.; Funding acquisition, M.F.; Investigation, S.Y. and O.A.; Methodology, S.Y. and M.R.; Project administration, M.F., M.R., and L.P.; Resources, M.F. and M.R.; Software, S.Y. and O.A.; Validation, M.F., M.R., and L.P.; Writing—original draft, S.Y.; Writing-review \& editing, M.F., M.R., A.F., and L.P. All authors have read and agreed to the published version of the manuscript.

Funding: This research was funded by the Italian Ministry of Education, University, and Research (MIUR) who provided financial support for a PhD fellowship in the frame of the research project entitled "Dipartimenti di Eccellenza" per Ingegneria Civile Edile e Ambientale, grant number: CUPE65D18000820006.

Acknowledgments: Sicong Yao would like to thank the Castaldo High Tech S.p.A. plant sited in Giugliano, Italy for the digestate material support and research study support.

Conflicts of Interest: The authors declare that they have no conflict of interest.

\section{References}

1. Deng, H.; Lu, J.; Li, G.; Zhang, G.; Wang, X. Adsorption of methylene blue on adsorbent materials produced from cotton stalk. Chem. Eng. J. 2011, 172, 326-334. [CrossRef] 
2. Gok, O.; Ozcan, A.S.; Ozcan, A. Adsorption behavior of a textile dye of Reactive Blue 19 from aqueous solutions onto modified bentonite. Appl. Surf. Sci. 2010, 256, 5439-5443. [CrossRef]

3. Vakili, M.; Rafatullah, M.; Salamatinia, B.; Abdullah, A.Z.; Ibrahim, M.H.; Tan, K.B.; Gholami, Z.; Amouzgar, P. Application of chitosan and its derivatives as adsorbents for dye removal from water and wastewater: A review. Carbohydr. Polym. 2014, 113, 115-130. [CrossRef] [PubMed]

4. Malash, G.F.; El-Khaiary, M.I. Methylene blue adsorption by the waste of Abu-Tartour phosphate rock. J. Colloid Interface Sci. 2010, 348, 537-545. [CrossRef] [PubMed]

5. Pan, Y.; Wang, Y.; Zhou, A.; Wang, A.; Wu, Z.; Lv, L.; Li, X.; Zhang, K.; Zhu, T. Removal of azo dye in an up-flow membrane-less bioelectrochemical system integrated with bio-contact oxidation reactor. Chem. Eng. J. 2017, 326, 454-461. [CrossRef]

6. Edison, T.N.J.I.; Lee, Y.R.; Sethuraman, M.G. Green synthesis of silver nanoparticles using Terminalia cuneata and its catalytic action in reduction of direct yellow-12 dye. Spectrochim. Acta A 2016, 161, 122-129. [CrossRef]

7. De Gisi, S.; Lofrano, G.; Grassi, M.; Notarnicola, M. Characteristics and adsorption capacities of low-cost sorbents for wastewater treatment: A review. Sustain. Mater. Technol. 2016, 9, 10-40. [CrossRef]

8. Kausar, A.; Iqbal, M.; Javed, A.; Aftab, K.; Nazli, Z.-i.-H.; Bhatti, H.N.; Nouren, S. Dyes adsorption using clay and modified clay: A review. J. Mol. Liq. 2018, 256,395-407. [CrossRef]

9. Ozcan, A.; Oncu, E.M.; Ozcan, A.S. Adsorption of acid blue 193 from aqueous solutions onto DEDMA-sepiolite. J. Hazard. Mater. 2006, 129, 244-252. [CrossRef]

10. Berrazoum, A.; Marouf, R.; Ouadjenia, F.; Schott, J. Bioadsorption of a reactive dye from aqueous solution by municipal solid waste. Biotechnol. Rep. 2015, 7, 44-50. [CrossRef]

11. Monteiro, A.; Jarrais, B.; Rocha, I.M.; Pereira, C.; Pereira, M.F.R.; Freire, C. Efficient immobilization of montmorillonite onto cotton textiles through their functionalization with organosilanes. Appl. Clay Sci. 2014, 101, 304-314. [CrossRef]

12. Zhou, L.; Zhou, H.; Hu, Y.; Yan, S.; Yang, J. Adsorption removal of cationic dyes from aqueous solutions using ceramic adsorbents prepared from industrial waste coal gangue. J. Environ. Manag. 2019, 234, 245-252. [CrossRef] [PubMed]

13. Njoku, V.O.; Foo, K.Y.; Asif, M.; Hameed, B.H. Preparation of activated carbons from rambutan (Nephelium lappaceum) peel by microwave-induced $\mathrm{KOH}$ activation for acid yellow 17 dye adsorption. Chem. Eng. J. 2014, 250, 198-204. [CrossRef]

14. Garg, A.; Mainrai, M.; Bulasara, V.K.; Barman, S. Experimental investigation on adsorption of amido black 10B dye onto zeolite synthesized from fly ash. Chem. Eng. Commun. 2015, 202, 123-130. [CrossRef]

15. Qiu, M.; Qian, C.; Xu, J.; Wu, J.; Wang, G. Studies on the adsorption of dyes into clinoptilolite. Desalination 2009, 243, 286-292. [CrossRef]

16. Hosseini Koupaie, E.; Eskicioglu, C. Health risk assessment of heavy metals through the consumption of food crops fertilized by biosolids: A probabilistic-based analysis. J. Hazard. Mater. 2015, 300, 855-865. [CrossRef]

17. Sakar, H.; Celik, I.; Balcik-Canbolat, C.; Keskinler, B.; Karagunduz, A. Ammonium removal and recovery from real digestate wastewater by a modified operational method of membrane capacitive deionization unit. J. Clean. Prod. 2019, 215, 1415-1423. [CrossRef]

18. Hu, Q.; Xu, Z.; Qiao, S.; Haghseresht, F.; Wilson, M.; Lu, G.Q. A novel color removal adsorbent from heterocoagulation of cationic and anionic clays. J. Colloid Interface Sci. 2007, 308, 191-199. [CrossRef]

19. Hong, S.; Ratpukdi, T.; Sungthong, B.; Sivaguru, J.; Khan, E. A sustainable solution for removal of glutaraldehyde in saline water with visible light photocatalysis. Chemosphere 2019, 220, 1083-1090. [CrossRef]

20. Kheirabadi, M.; Samadi, M.; Asadian, E.; Zhou, Y.; Dong, C.; Zhang, J.; Moshfegh, A.Z. Well-designed $\mathrm{Ag} / \mathrm{ZnO} / 3 \mathrm{D}$ graphene structure for dye removal: Adsorption, photocatalysis and physical separation capabilities. J. Colloid Interface Sci. 2019, 537, 66-78. [CrossRef]

21. Sharma, P.; Borah, D.J.; Das, P.; Das, M.R. Cationic and anionic dye removal from aqueous solution using montmorillonite clay: Evaluation of adsorption parameters and mechanism. Desalin. Water Treat. 2016, 57, 8372-8388. [CrossRef]

22. Sözüdoğru, O.; Fil, B.A.; Boncukcuoğlu, R.; Aladağ, E.; Kul, S. Adsorptive removal of cationic (BY2) dye from aqueous solutions onto Turkish clay: Isotherm, kinetic, and thermodynamic analysis. Particul. Sci. Technol. 2016, 34, 103-111. [CrossRef] 
23. Fu, D.; Chen, Z.; Xia, D.; Shen, L.; Wang, Y.; Li, Q. A novel solid digestate-derived biochar-Cu NP composite activating $\mathrm{H} 2 \mathrm{O} 2$ system for simultaneous adsorption and degradation of tetracycline. Environ. Pollut. 2017, 221, 301-310. [CrossRef] [PubMed]

24. Yin, J.; Pei, M.; He, Y.; Du, Y.; Guo, W.; Wang, L. Hydrothermal and activated synthesis of adsorbent montmorillonite supported porous carbon nanospheres for removal of methylene blue from waste water. RSC Adv. 2015, 5, 89839-89847. [CrossRef]

25. Zemaitaitiene, R.J.; Zliobaite, E.; Klimaviciute, R.; Zemaitaitis, A. The role of anionic substances in removal of textile dyes from solutions using cationic flocculant. Colloids Surf. Physicochem. Eng. Aspects 2003, 214, 37-47. [CrossRef]

26. Makhoukhi, B.; Djab, M.; Amine Didi, M. Adsorption of Telon dyes onto bis-imidazolium modified bentonite in aqueous solutions. J. Environ. Chem. Eng. 2015, 3, 1384-1392. [CrossRef]

27. Yang, Z.; Li, M.; Yu, M.; Huang, J.; Xu, H.; Zhou, Y.; Song, P.; Xu, R. A novel approach for methylene blue removal by calcium dodecyl sulfate enhanced precipitation and microbial flocculant GA1 flocculation. Chem. Eng. J. 2016, 303, 1-13. [CrossRef]

28. Pirozzi, C.; Pontoni, L.; Fabbricino, M.; Bogush, A.; Campos, L.C. Effect of organic matter release from natural cork used on bisphenol a removal from aqueous solution. J. Clean. Prod. 2020, 244, 118675. [CrossRef]

29. Fan, L.; Chen, Y.; Wang, L.; Jiang, W. Adsorption of Pb(II) Ions from aqueous solutions by pyrolusite-modified activated carbon prepared from sewage sludge. Adsorpt. Sci. Technol. 2011, 29, 495-506. [CrossRef]

30. Fogg, A.G.; Rahim, A.; Yusoff, H.M.; Ahmad, R. Cathodic stripping voltammetry of copper-complexed reactive dyes at a hanging mercury drop electrode: Reactive violet 5. Talanta 1997, 44, 125-129. [CrossRef]

31. Jiang, R.; Zhu, H.; Li, X.; Xiao, L. Visible light photocatalytic decolourization of C. I. Acid Red 66 by chitosan capped CdS composite nanoparticles. Chem. Eng. J. 2009, 152, 537-542. [CrossRef]

32. Melo, R.P.F.; Barros Neto, E.L.; Moura, M.C.P.A.; Castro Dantas, T.N.; Dantas Neto, A.A.; Oliveira, H.N.M. Removal of direct Yellow 27 dye using animal fat and vegetable oil-based surfactant. J. Water Process Eng. 2015, 7, 196-202. [CrossRef]

33. Wang, W.; Bai, H.; Zhao, Y.; Kang, S.; Yi, H.; Zhang, T.; Song, S. Synthesis of chitosan cross-linked 3D network-structured hydrogel for methylene blue removal. Int. J. Biol. Macromol. 2019, 141, 98-107. [CrossRef]

34. Doke, K.M.; Khan, E.M. Equilibrium, kinetic and diffusion mechanism of Cr(VI) adsorption onto activated carbon derived from wood apple shell. Arab. J. Chem. 2017, 10, S252-S260. [CrossRef]

35. Islam, M.A.; Ali, I.; Karim, S.M.A.; Hossain Firoz, M.S.; Chowdhury, A.-N.; Morton, D.W.; Angove, M.J. Removal of dye from polluted water using novel nano manganese oxide-based materials. J. Water Process Eng. 2019, 32, 100911. [CrossRef]

36. Agarwal, S.; Tyagi, I.; Gupta, V.K.; Ghasemi, N.; Shahivand, M.; Ghasemi, M. Kinetics, equilibrium studies and thermodynamics of methylene blue adsorption on Ephedra strobilacea saw dust and modified using phosphoric acid and zinc chloride. J. Mol. Liq. 2016, 218, 208-218. [CrossRef]

37. Postai, D.L.; Demarchi, C.A.; Zanatta, F.; Melo, D.C.C.; Rodrigues, C.A. Adsorption of rhodamine B and methylene blue dyes using waste of seeds of Aleurites Moluccana, a low cost adsorbent. Alex. Eng. J. 2016, 55, 1713-1723. [CrossRef]

38. Hammed, A.K.; Dewayanto, N.; Du, D.; Ab Rahim, M.H.; Nordin, M.R. Novel modified ZSM-5 as an efficient adsorbent for methylene blue removal. J. Environ. Chem. Eng. 2016, 4, 2607-2616. [CrossRef]

39. Fosso-Kankeu, E.; Mittal, H.; Mishra, S.B.; Mishra, A.K. Gum ghatti and acrylic acid based biodegradable hydrogels for the effective adsorption of cationic dyes. J. Ind. Eng. Chem. 2015, 22, 171-178. [CrossRef]

40. Moradi, M.; Ghanbari, F.; Manshouri, M.; Angali, K.A. Photocatalytic degradation of azo dye using nano-ZrO 2/UV/Persulfate: Response surface modeling and optimization. Korean J. Chem. Eng. 2016, 33, 539-546. [CrossRef]

41. Anastopoulos, I.; Kyzas, G.Z. Agricultural peels for dye adsorption: A review of recent literature. J. Mol. Liq. 2014, 200, 381-389. [CrossRef]

42. Qian, J.; Shen, M.; Wang, P.; Wang, C.; Li, K.; Liu, J.; Lu, B.; Tian, X. Perfluorooctane sulfonate adsorption on powder activated carbon: Effect of phosphate (P) competition, $\mathrm{pH}$, and temperature. Chemosphere 2017, 182, 215-222. [CrossRef] [PubMed]

43. Yagub, M.T.; Sen, T.K.; Afroze, S.; Ang, H.M. Dye and its removal from aqueous solution by adsorption: A review. Adv. Colloid Interface Sci. 2014, 209, 172-184. [CrossRef] [PubMed] 
44. Domingues, V.; Alves, A.; Cabral, M.; Delerue-Matos, C. Sorption behaviour of bifenthrin on cork. J. Chromatogr. 2005, 1069, 127-132. [CrossRef]

45. Brar, S.K.; Wangoo, N.; Sharma, R.K. Enhanced and selective adsorption of cationic dyes using novel biocompatible self-assembled peptide fibrils. J. Environ. Manag. 2020, 255, 109804. [CrossRef]

46. Fomina, M.; Gadd, G.M. Biosorption: Current perspectives on concept, definition and application. Bioresour. Technol. 2014, 160, 3-14. [CrossRef]

47. Wang, J.; Chen, C. Biosorbents for heavy metals removal and their future. Biotechnol. Adv. 2009, 27, $195-226$. [CrossRef]

48. Jain, S.N.; Tamboli, S.R.; Sutar, D.S.; Jadhav, S.R.; Marathe, J.V.; Shaikh, A.A.; Prajapati, A.A. Batch and continuous studies for adsorption of anionic dye onto waste tea residue: Kinetic, equilibrium, breakthrough and reusability studies. J. Clean. Prod. 2020, 252, 119778. [CrossRef]

49. Kizito, S.; Wu, S.; Kipkemoi Kirui, W.; Lei, M.; Lu, Q.; Bah, H.; Dong, R. Evaluation of slow pyrolyzed wood and rice husks biochar for adsorption of ammonium nitrogen from piggery manure anaerobic digestate slurry. Sci. Total Environ. 2015, 505, 102-112. [CrossRef]

50. Ma, T.; Wu, Y.; Liu, N.; Wu, Y. Hydrolyzed polyacrylamide modified diatomite waste as a novel adsorbent for organic dye removal: Adsorption performance and mechanism studies. Polyhedron 2020, 175, 114227. [CrossRef]

51. Isah, A.U.; Abdulraheem, G.; Bala, S.; Muhammad, S.; Abdullahi, M. Kinetics, equilibrium and thermodynamics studies of C.I. Reactive Blue 19 dye adsorption on coconut shell based activated carbon. Int. Biodeterior. Biodegrad. 2015, 102, 265-273. [CrossRef]

52. Galán, J.; Rodríguez, A.; Gómez, J.M.; Allen, S.J.; Walker, G.M. Reactive dye adsorption onto a novel mesoporous carbon. Chem. Eng. J. 2013, 219, 62-68. [CrossRef]

53. Yao, S.; Wang, M.; Liu, J.; Tang, S.; Chen, H.; Guo, T.; Yang, G.; Chen, Y. Removal of phosphate from aqueous solution by sewage sludge-based activated carbon loaded with pyrolusite. J. Water Reuse Desalin. 2017, 8, 192-201. [CrossRef]

54. El Boundati, Y.; Ziat, K.; Naji, A.; Saidi, M. Generalized fractal-like adsorption kinetic models: Application to adsorption of copper on Argan nut shell. J. Mol. Liq. 2019, 276, 15-26. [CrossRef]

55. Guo, X.; Wang, J. A general kinetic model for adsorption: Theoretical analysis and modeling. J. Mol. Liq. 2019, 288, 111100. [CrossRef]

56. Rangabhashiyam, S.; Anu, N.; Selvaraju, N. Sequestration of dye from textile industry wastewater using agricultural waste products as adsorbents. J. Environ. Chem. Eng. 2013, 1, 629-641. [CrossRef]

(C) 2020 by the authors. Licensee MDPI, Basel, Switzerland. This article is an open access article distributed under the terms and conditions of the Creative Commons Attribution (CC BY) license (http://creativecommons.org/licenses/by/4.0/). 